\title{
A Review on Smart Meter System
}

\author{
Patel Umang $\mathbf{M}^{1}$, Modi Mitul $\mathbf{M}^{2}$ \\ PG Scholar, Department of Electrical Engineering, Ganpat University, Kherva, India ${ }^{1}$ \\ Assistant Professor, Department of Electrical Engineering, Ganpat University, Kherva, India ${ }^{2}$
}

\begin{abstract}
The present system of energy metering as well as billing in India uses electromechanical and somewhere digital energy meter. It consume more time and labour. One of the prime reasons is the tradition billing system which is incorrect. Many times slow, costly and lack in flexibility as well as reliability. Today accuracy in electrical billing is highly recommended. The smart energy meter gives real time consumption as well as accurate billing. A possible solution is a Wireless Energy Meter which is able to send its data via wireless communication to PC or a remote device where monitoring and analysis of the data will be easily made. In smart metering there is a different technique in communication system like AMI, WIMAX, and Zig-bee etc. This paper presents a brief literature review of the work carried out by the various researchers in this field by using AMI techniques. And also the various communication system used in smart metering technology.
\end{abstract}

Keywords: AMI, GSM, Zig-bee, WIMAX.

\section{INTRODUCTION}

Energy meters in India have dominantly been electromechanical in nature but are gradually being replaced by more sophisticated and accurate digital and electronic meters. A high percentage of electricity revenue is lost to power theft, incorrect meter reading and billing, and reluctance of consumers towards paying electricity bills on time. Considerable amount of revenue losses can be reduced by using prepaid energy meters.

The smart meters known today are simply automated reading units, or ARU, capable of computing the power consumption and cost for the consumption in accordance to the time of the day, and day of the week. On other hand, the advanced metering infrastructure, or AMI, is a system of utility meters that measure the consumption and provide the information to the utility companies, as well as the consumers interested in keeping the usage costs low, or wanting to supply the electricity back to the grid [1]. As for the energy efficiency issues of smart metering devices, since most smart metering devices adopted wireless communications such as Zig-Bee and Wireless Sensor Network (WSN) based on IEEE802.15.4[2].

Smart meters are being introduced in many power systems world-wide to provide real time power consumption and price information to consumers. Smart Meters are electronic measurement devices used by utilities to communicate information for billing customers and operating their electric systems. The combination of the electronic meters with two-way communications technology for information, monitor, and control is commonly referred to as Advanced Metering infrastructure (AMI). Previous systems, which utilized one-way communications to collect meter data, were referred to as AMR (Automated Meter Reading) Systems. AMI has developed over time, from its roots as a metering reading substitute (AMR) to today's two- way communication and data system. This paper proposes the use of smart meters in distributed generation which is still more advanced than the existing methods providing efficient transmission and evacuation of power [7].

\section{THE CONCEPT ON SMART GRID AND SMART METERING}

The term "smart grid" is generally used to represent the integration of all supply, grid, and demand elements connected to a digital upgrade of power grid with a reliable, resilient, secure, and manageable standards-based open information infrastructure which can provide twoway communications to offer numerous benefits for both the power suppliers and consumers.

The Smart Grid uses intelligent devices and a digital communication upgraded power system to enhance the performance of transmission and distribution grids. Using this digital technology, the intelligent systems can assess its health in real-time, accommodate new environments, control distributed resource integrations and optimize the response of smart appliances of end users. The efficiency and reliability can be improved and active roles from end users can be used in Smart Grid in order to save consumers' money [9].

Implementation of automated meter reading (AMR) equipment has been established since so many years ago. In those years, wireless equipment or phone lines were used to transfer data. This equipment were designed in a way that data were collected by a radio link installed in a vehicle passing along the street near the meter, or through phone lines or wireless channels receiving data from meters.

Smart meters must be capable of metering basic and other useful parameters. These meters must be able to provide proper communication ports to respond to requests for collecting necessary data, to commands issued by the central access server to switch on or off, and, in case of any manipulation, to report any events and faults. This meter must have an interface to connect the In Home Display (IHD) for customer awareness. A smart meter should be capable of showing the total cost of the consumed energy. Also, it should be able to register data related to consumption per hour, allowing the subscribers to manage their consumption. 
INTERNATIONAL JOURNAL OF INNOVATIVE RESEARCH IN ELECTRICAL, ELECTRONICS, INSTRUMENTATION AND CONTROL ENGINEERING Vol. 3, Issue 12, December 2015

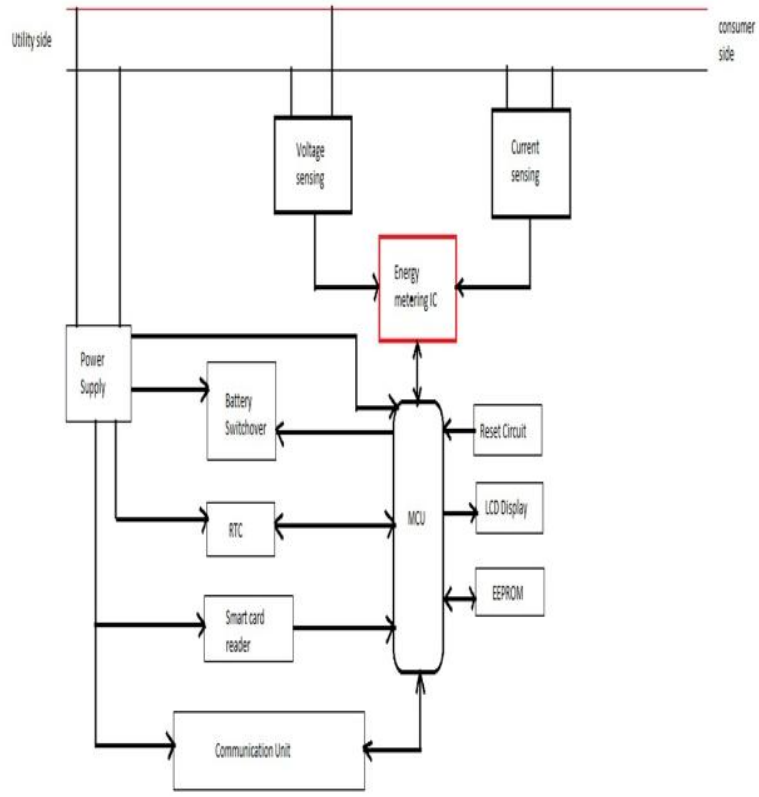

Fig.1. Hardware structure of a modern smart meter

Communication networks are able to send the control commands issued by the station to the smart meter and to transfer the data collected by the meter to the central access server. The most important advantage of investing in smart metering systems is saving the cost of the distribution system function. In case of constant and continuous reading, and the need for powering on/off of subscribers as a result of not paying the bills or powering on after solving the problem, utility would not need to dispatch an expert to the place; all of this can be done by smart meters. This can reduce the annual expenditure of utility to a great amount.

Using Home Area Network (HAN), indoor displays to show the information about the consumption, this system can inform the subscriber as to how to use energy in peak time, which can reduce the subscribers charge. AMI consists of a set of equipment, networks, computer systems, protocols and organized processes which are employed to collect and send data related to electricity consumption of the subscribers using power and distribution grid. We call this system advanced because not only it can collect data but also it is so secure, safe and fast, self-upgradable and developed. AMI technology enables the utility to do several functions accurately and correctly [15].

\section{III.ADVANCED METERING INFRASTRUCTURE} (AMI)

AMI is not a single technology; rather it is a configured infrastructure that integrates a number of technologies to achieve its goals. The infrastructure includes smart meters at the consumer end, communication networks at different levels of the infrastructure hierarchy to connect two ends, Meter Data Management Systems (MDMS) and the means to integrate the collected data into software application platforms and interfaces at utility provider or head end [4].

The implementing the smart meter can range from monitoring and controlling the consumptions of the utilities at their connection to a building, to monitoring and controlling the outlets to all the appliances in the building. It is assumed that each component of the AMI is modular and driven by the intelligent agent. Since, the customer would be empowered to use each component separately as well as in a system, and the modularity of AMI would allow for meshing the metering and control framework to produce a robust system. The intelligent multi-agent AMI can be programmed to provide the standard performance indicators of the system: Specific, Measurable, Accurate, Relevant, Timely, Evaluative, and Recordable. The utility companies would need to install a single device at the conventional position of a particular utility meter and be able to receive the standard consumption trends at set intervals [1].

The customer is equipped with an advanced solid state electronic meter that collects time-based data. These meters can transmit the collected data through commonly available fixed networks. The metered data are received by the AMI host system. Subsequently, they are sent to a MDMS that manages data storage, analyses and provides the information in a useful form to the utility service provider. AMI enables two-way communication; therefore, communication or issuance of command or price signals from the utility provider to the meter or load controlling devices are also possible [5].

\section{IV.PROPOSED METHOD OF WIRELESS COMMUNICATION IN SMART METERING}

\section{A. GSM Short Messaging}

Global System for Mobile Communications (GSM) is the world's most popular standard for mobile telephony systems .GSM is used by over 1.5 billion people across more than 212 countries and territories. GSM also pioneered low-cost implementation of the short message service (SMS) which allows parties to exchange delay tolerant short text messages. The popularity and wide coverage of cellular networks have attracted researchers to consider the use of SMS service. However there are certain questionable issues regarding GSM network such as its scalability, reliability and security, especially under high load. Zerfos et al (2006) have analyzed real data taken from a real GSM network in India. SMS delivery success rate was found to be $94.9 \% ; 73.2 \%$ of the successfully delivered messages reach to the destination within 10 seconds; about $5 \%$ of them require more than an hour and a half. Using SMS for AMR service will definitely increase the flow of messages tremendously. GSM uses several cryptographic algorithms for security. The development of UMTS introduces an optional Universal Subscriber Identity Module (USIM), which uses a longer authentication key to give greater security, as well as mutually authenticating the network and the user [14].

\section{B. Zig-bee}

There are various topologies for communication in Smart Grid. The most practiced architecture is to collect the data from groups of meters in local data concentrators and then transmit them using a backhaul channel to central command, where the servers, data storing and processing facilities as well as management and billing applications 
reside. Since different types of architecture and networks enable low power transmission, wireless technologies are are available for realization of AMI, there are various the dominant solutions for HANs. These technologies mediums and communication technologies for this include $2.4 \mathrm{GHz}$ WI-Fi, 802.11 wireless networking purpose as well: Power Line Carrier (PLC), Broadband protocols, Zig-Bee and HomePlug. Zig-bee is based on the over power lines (BPL), copper or optical-fiber, and wireless IEEE 802.15.4 standard and is technologically cellular, WiMAX, Bluetooth, GPRS, Peer-to-Peer, Zig-bee similar to Bluetooth. HomePlug, on the other hand, and a few others. At AMI level, communications are transmits data over the existing electrical wiring at the between devices in a home while at upper layer, they home. There is still no unique standard or practice for inoccur between Home Area Networks (HAN) and the home communication on the market; however, Zig-bee utility provider. These two, in short, could be called inhome and utility networks.

HANs connect smart meters, smart devices within the home premises, energy storage and generation (solar, wind, etc.), electric vehicles as well as IHD and controllers together. Since their data flow is instantaneous rather than continuous, HANs required bandwidth varies from 10 to $100 \mathrm{kbps}$ for each device, depending on the task. The network, however, should be expandable as the number of devices or data rate may increase to cover office buildings or large houses. The calculated reliability and accepted delay are also based on the consideration that the loads and usage are not critical. Given the above requirements and considering the short distances among nodes that and to lesser extent HomePlug and Z-Wave are the dominant solutions. Advantages of Zig-bee include providing wireless communication, low power consumption, flexibility and economic efficiency. The main disadvantage of Zig-bee is the low bandwidth. In commercial buildings, a wired technology named BACnet is the prominent communication protocol. Recently, a wireless version of BACnet has become available using short range wireless networks such as Zig-bee [5].

\section{WIMAX}

In the smart grid smart meters, home gateways, and consumer devices server and respective clients communicate via wireless communication.

\section{TABLE I COMPARISON OF DIFFERENT SMART GRID WIRELESS TECHNOLOGY}

\begin{tabular}{|c|c|c|c|c|}
\hline Description & WIMAX & Power Line Carrier & WLAN & Zig-bee \\
\hline $\begin{array}{l}\text { General } \\
\text { usage }\end{array}$ & $\begin{array}{l}\text { Point-to-point } \\
\text { wireless } \\
\text { transport for } \\
\text { voice, data, } \\
\text { video, etc. }\end{array}$ & $\begin{array}{l}\text { Also known as power line } \\
\text { communication, Broadband } \\
\text { over Power Lines; Systems } \\
\text { for carrying data on a } \\
\text { power conductor, for WAN } \\
\text { applications; }\end{array}$ & $\begin{array}{l}\text { Wireless networking } \\
\text { for LAN and WAN; } \\
\text { widely used for } \\
\text { indoor } \quad \text { wireless } \\
\text { LAN. }\end{array}$ & $\begin{array}{l}\text { Low data rate, long } \\
\text { battery life and secure } \\
\text { networking; In-between } \\
\text { Wi-Fi and Bluetooth. }\end{array}$ \\
\hline $\begin{array}{l}\text { Frequency } \\
\text { range }\end{array}$ & $\begin{array}{l}2.3,2.5,3.5 \\
\text { GHz licensed } \\
\text { bands; } 450 \\
\text { MHz, } 700 \\
\text { MHz also used }\end{array}$ & $\begin{array}{l}1.7-80 \mathrm{MHz} \text {. Most } \\
\text { providers rely on the } 1-30 \\
\text { MHz spectrum bandwidth } \\
\text { for BPL transmission. }\end{array}$ & $\begin{array}{lr}\text { Unlicensed: } & 2.4 \text { and } \\
5 \quad \mathrm{GHz} ; & \text { Direct } \\
\text { Sequence } & \text { Spread } \\
\text { Spectrum } & \text { (DSSS), } \\
\text { OFDM } & \end{array}$ & $\begin{array}{l}868 \mathrm{MHz}, 915 \mathrm{MHz}, \\
\text { 2.4 GHz (unlicensed); } \\
\text { Direct Sequence Spread } \\
\text { Spectrum coding. }\end{array}$ \\
\hline $\begin{array}{c}\text { Channel } \\
\text { bandwidth }\end{array}$ & $\begin{array}{l}20 \text { or } 25 \mathrm{MHz} \\
\text { (United } \mathrm{States} \text { ) } \\
\text { or } 28 \mathrm{MHz} \\
\text { (Europe) }\end{array}$ & $\begin{array}{l}\text { Wide band } 1200(\mathrm{~Hz}) \\
\text { Medium band } 600(\mathrm{~Hz})\end{array}$ & $\begin{array}{l}20 \mathrm{MHz} \text { for } 802.11 \\
\mathrm{a} / \mathrm{g} ; 20 / 40 \mathrm{MHz} \text { for } \\
802 \text {. }\end{array}$ & $\begin{array}{l}\text { Nominal bandwidth of } \\
22 \mathrm{MHz} \text {. }\end{array}$ \\
\hline $\begin{array}{l}\text { Coverage } \\
\text { capabilities }\end{array}$ & $\begin{array}{l}\text { 3-4 miles; } \\
\text { longer } \\
\text { distances } \\
\text { capable with } \\
\text { lower bit rates }\end{array}$ & $\begin{array}{l}\text { Distances of more than } 15 \\
\mathrm{~km} \text { can be achieved over a } \\
\text { medium voltage network }\end{array}$ & $\begin{array}{l}\text { Indoor: up to } 100 \mathrm{~m} \text {; } \\
\text { Outdoor: up to } 250 \\
\mathrm{~m}\end{array}$ & Up to 50 meters \\
\hline $\begin{array}{l}\text { Peak single } \\
\text { user data } \\
\text { rate }\end{array}$ & $\begin{array}{l}\text { Typical 4-16 } \\
\text { Mbps }\end{array}$ & $\begin{array}{l}\text { Low-frequency }(100-200 \\
\mathrm{kHz}) \text { carriers: Few hundred } \\
\text { bits per second; Higher } \\
\text { data rates mean shorter } \\
\text { ranges. Speeds up to } 10 \\
\text { Mbps have been achieved. }\end{array}$ & $\begin{array}{l}\text { 802.11b: up to } 11 \\
\text { Mbps; } \\
802.11 \mathrm{a} / \mathrm{g} / \mathrm{h} / \mathrm{j}: \text { up to } \\
54 \mathrm{Mbps;} 802.11 \mathrm{n} \text { : } \\
>100 \mathrm{Mbps}\end{array}$ & $\begin{array}{l}20 \text { to } 250 \text { kbps, } \\
\text { depending on frequency } \\
\text { band. }\end{array}$ \\
\hline Cost & Moderate & $\begin{array}{l}\text { High cost of } \\
\text { implementation and lack of } \\
\text { vendors. }\end{array}$ & $\begin{array}{l}\text { Low - widely used } \\
\text { and deployed in the } \\
\text { consumer market. }\end{array}$ & $\begin{array}{l}\text { Low - intended as a low } \\
\text { cost, low power product } \\
\text { for low bandwidth } \\
\text { applications. }\end{array}$ \\
\hline $\begin{array}{l}\text { Technology } \\
\text { maturity }\end{array}$ & $\begin{array}{l}\text { Mature; 500+ } \\
\text { deployments } \\
\text { worldwide. }\end{array}$ & $\begin{array}{l}\text { More popular in Europe } \\
\text { than North America. }\end{array}$ & $\begin{array}{l}\text { Wi-Fi is a mature, } \\
\text { proven interoperable } \\
\text { technology. }\end{array}$ & $\begin{array}{ll}\text { Fairly } & \text { new; } \\
\text { specifications ratified in } \\
2004, & \text { ongoing } \\
\text { specifications still in } \\
\text { process. }\end{array}$ \\
\hline
\end{tabular}


Moreover consumer can become small-scale suppliers by generating green energy at home, consume this power locally and sell the excess power to the utilities. The emerging IEEE 802.16 Broadband Wireless Access technology WIMAX allows interoperability and combines the benefits that other wireless networking technologies offer individually and leads a path towards $4 \mathrm{G}$.

The WIMAX spectrum uses for voice, video, and data all considered broad band Wireless Access applications. WIMAX technology enables ubiquitous delivery of wireless broadband service for fixed and/or mobile users, and became a reality in 2006 when Korea Telecom started the deployment of a $2.3 \mathrm{GHz}$ version of mobile WIMAX service called WI- BRO in the Seoul metropolitan area to offer high performance for data and video up to $50 \mathrm{~km}$. Utility needs and problems are often formulated in very loose terms, such as "intelligent load shedding," "protection system against major disturbances," and "counteract cascaded line tripping." These needs have to be broken down to physical phenomena, such as protection against: transient angle instability (first swing), small signal angle instability (damping), frequency instability, short-term voltage instability, long-term voltage instability, cascading outages. The most fundamental requirement in any electrical system is proper over current protection to prevent the load from overheating and electrodynamics interactions. This article provide a detail client server bidirectional load protection system model for wide area Smart Grid network and focus on over current Power System Load Protection implementation in MATLAB/SIMULINK using WIMAX. The paper also highlights WIMAX transmitter and receiver model for desired wide area monitoring and control [11]

\section{CONCLUSION}

Energy meters in India have dominantly been electromechanical in nature but are gradually being replaced by more sophisticated and accurate digital and electronic meters. A high percentage of electricity revenue is lost to power theft, incorrect meter reading and billing, and reluctance of consumers towards paying electricity bills on time. In this paper brief introduction about smart grid and smart meter are given and also the advance metering infrastructure discussed. Here various wireless communication used in smart meter technology is described and also the comparison of four different technology is given. Here we conclude that PLC method has high initial cost and Zig-bee method has low cost, long battery life and more secure so Zig-bee method is more preferable for smart metering communication application.

\section{REFERENCES}

1] Daniel Bondarenko and Hossam Gaber, "Simulation Analysis for the Design of High Performance Smart Meter", IEEE International Conference on Smart Grid Engineering (SGE'12), UOIT, Oshawa, ON, 27- 29 August, 2012.

[2] Kwang-Soon Choi and Sukil Hong, "New Design Approaches and Implementation of Smart Metering System", IEEE ISCE 2014.

[3] Engr. Bilal shahid, Zubair Ahmed, Adnan Faroqi and Rao M. Navid-ur-Rehman, "Implementation of Smart System based on Smart Grid Smart Meter And Smart Appliances",2nd Iranian Conference on Smart Grid, May 23\&24,2012, Tehran,Iran( Icse 2012).
[4] Libiao Qiao, Xiaojun Liu and Baochen Jiang, "Design and Implementation of the Smart Meter in Vehicle-to-Grid", IEEE 2012

[5] Alan S. Fung, Farah Mohammadi, and Kaamran Raahemifar and Ramyar Rashed Mohassel, "A Survey on Advanced Metering Infrastructure and its Application in Smart Grids ", IEEE CCECE 2014

[6] Amit Jain and Mohnish Bagree, "A prepaid meter using mobile communication",International Journal of Engineering, Science and Technology Vol. 3, No. 3, pp. 160-166, 2011.

[7] Mr.P.Gokula Krishnan and Ms.K.Arunachaleswari, "Distributed Generation Grid Infrastructure using Smart Meters Modeled with Renewable Energy Sources and Power Trading "ISSN: 2277-9655 Impact Factor: 1.852, December, 2013.

[8] Fan Cai, David J.Chung, Evangelos Farantatos, A.P. Sakis Meliopoulos and John Papapolymerou "Self- powered Advanced Meter Design for Smart Grid”, IEICE Conference TH3G-29,2010.

[9] C. Gao and M. A. Redfern, "A Review of Voltage Control in Smart Grid and Smart Metering Technologies on Distribution Networks", 46th International Universities' Power Engineering Conference, ISBN 978-3-8007-3402-3,8th September 2011.

10] O.Homa Kesav and B. Abdul Rahim, "Automated Wireless Meter Reading System for Monitoring and Controlling Power Consumption", International Journal of Recent Technology and Engineering (IJRTE), ISSN: 2277-3878, Volume-1, Issue-2, June 2012.

[11] Asadullah Khan, Muhammad Ali, Ishtiaq Ahmad, Amjad Ullah, Haseeb Ur Rahman and Hafeez Ur Rahman "WIMAX Implementation of Smart Grid Wide Area Power System Load Protection Model in MATLAB/SIMULINK", scientific research Smart Grid and Renewable Energy 3, 282-293, November 2012.

[12] Rani T R, Raji Krishna, "Design and Analysis of a Grid Connected Renewable Home Energy System", International Journal of Engineering Research \& Technology (IJERT) IJERT IJERT ISSN: 2278-0181, Vol. 3 Issue 7, July - 2014.

[13] Mahesh S Narkhede, Dr.S.Chatterji and Dr.Smarajit Ghosh, "Challenges, Modeling Simulation and Performance Analysis of Virtual Power Plant in Indian Context",International Journal of Advanced Research in Electrical, Electronics and Instrumentation Engineering, Vol. 3, Issue 4, April 2014.

[14] B.O.Omijeh and G.I.Ighalo, "Modeling of GSM-Based Energy Recharge Scheme for Prepaid Meter", IOSR Journal of Electrical and Electronics Engineering, ISSN: 2278-1676 Volume 4, Issue 1 (Jan. - Feb. 2013), PP 46-53.

[15] Mehdi Arian, Mohammad Ameli, Vahid Soleimani and Shiva ghazalizadeh, "Intelligent Migration from Smart Metering to Smart Grid”, IEEE 978-1-4244-9690, 2011.

[16] Engr. Manzoor Ellahi, Prof. Dr. Suhail, A. Qureshi and Mustansir Iqbal "Power Factor Monitoring and Load Management Using Smart Metering Techniques", International Journal of Engineering Research \& Technology (IJERT), ISSN: 2278-0181, Vol. 2 Issue 12, December - 2013 